\title{
Access to early phase clinical trials for children with relapsed and refractory neuroblastoma. A multicentre international study.
}

\author{
Marta Cortes ${ }^{1}$, Fernando Carceller ${ }^{2}$, Alba Rubio-San-Simon ${ }^{3}$, Sucheta Vaidya ${ }^{4}$, Francisco \\ Bautista $^{5}$, and Lucas Moreno ${ }^{6}$ \\ ${ }^{1}$ Hospital Materno Infantil \\ ${ }^{2}$ Royal Marsden Hospital Sutton \\ ${ }^{3}$ Hospital Universitario 12 de Octubre \\ ${ }^{4}$ The Royal Marsden NHS Foundation trust \\ ${ }^{5}$ Hospital Infantil Universitario Nino Jesus \\ ${ }^{6}$ Vall d'Hebron Hospital
}

July 29, 2021

\begin{abstract}
Objectives. Neuroblastoma is the most common extracranial tumour in children, and prognosis for refractory and relapsed disease is still poor. Early Phase clinical trials play a pivotal role in the development of novel drugs. Ensuring adequate recruitment is crucial. The primary aim was to determine the rate of participation trials for children with refractory/relapsed neuroblastoma in two of the largest Drug Development European institutions. Methods. Data from patients diagnosed with refractory/relapsed neuroblastoma between January 2012 and December 2018 at the two institutions were collected and analysed. Results. Overall, 48 patients were included. A total of 31 (65\%) refractory/relapsed cases were enrolled in early Phase trials. The main reasons for not participating in clinical trials included: not fulfilling eligibility criteria prior to consent (12/17, $70 \%)$ and screening failure $(2 / 17,12 \%)$. Median time on trial was 4.3 months (range 0.6-13.4). Most common cause for trial discontinuation was disease progression (67.7\%). Median overall survival was longer in refractory (28 months, $95 \%$ CI, 20.9-40.2) than in relapsed patients (14 months, 95\% CI, 8.1-20.1)) [p=0,034]. Conclusions. Although two thirds of children with refractory/relapsed neuroblastoma were enrolled in early Phase trials, recruitment rates can still be improved. The main cause for not participating on trials was not fulfilling eligibility criteria prior to consent, mainly due to performance status and short life expectancy. This study highlights the hurdles to access to innovative therapies for children with relapsed/refractory neuroblastomas and identifies key areas of development to improve recruitment to early phase trials.
\end{abstract}

\section{Hosted file}

COVER LETTER.doc available at https://authorea.com/users/428290/articles/532182-access-toearly-phase-clinical-trials-for-children-with-relapsed-and-refractory-neuroblastoma-amulticentre-international-study

\section{Hosted file}

Access to early phase clinical trials neuroblastoma LAST.docx available at https://authorea. com/users/428290/articles/532182-access-to-early-phase-clinical-trials-for-childrenwith-relapsed-and-refractory-neuroblastoma-a-multicentre-international-study 


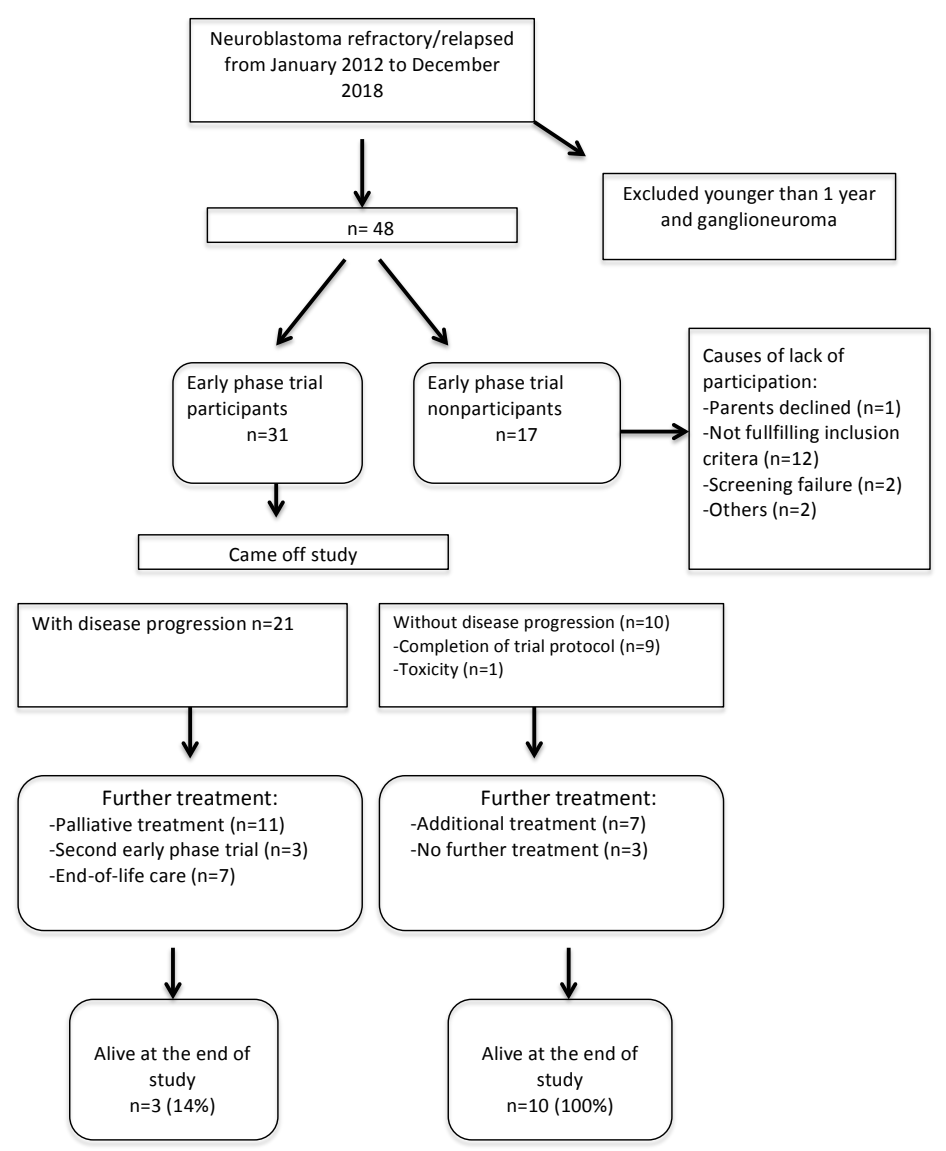

Figure 1. Consort diagram of the current study

\section{Hosted file}

Table 1 Baseline Patients_MC 4.0.docx available at https://authorea.com/users/428290/ articles/532182-access-to-early-phase-clinical-trials-for-children-with-relapsed-andrefractory-neuroblastoma-a-multicentre-international-study 


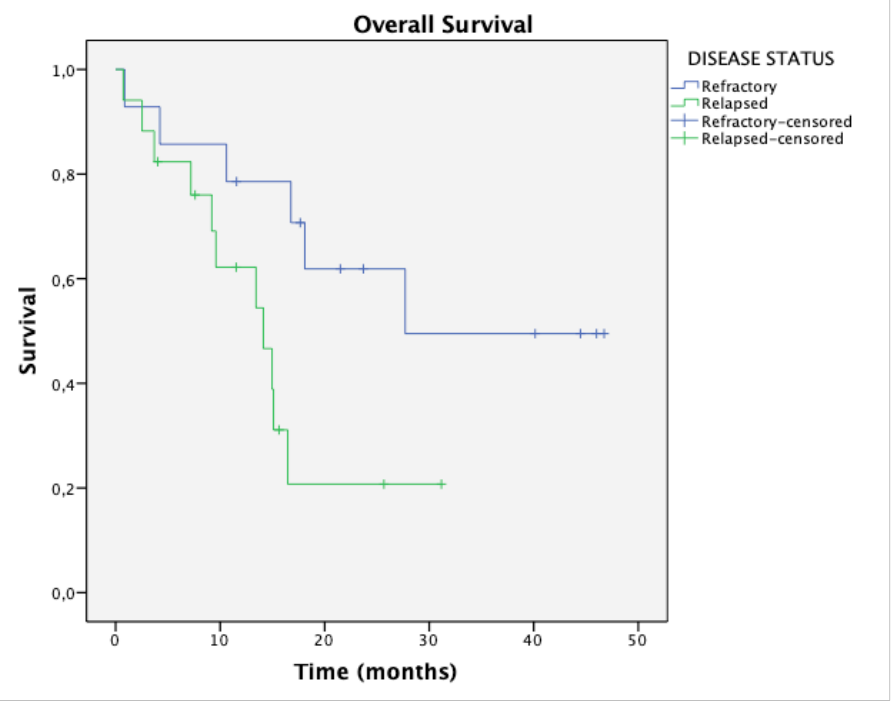

Figure 2. Kaplan-Meier curves for overall survival in patients with refractory and relapsed neuroblastoma participating in early-phase trials. 